SCRDSI-2021, Aravali Institute of Technical Studies, Udaipur (Rajasthan), India

International Journal of Technical Research \& Science (Special Issue) ISSN No.:2454-2024 (online)

\title{
AN OVERVIEW OF ELECTRICAL POWER DISTRIBUTION
}

\author{
Kamlesh Singh Tanwar ${ }^{1}$, Vinay Choubisa ${ }^{2}$ \\ E-Mail Id: kunnuthakor@gmail.com ${ }^{1}$, choubisavinay848@gmail.com ${ }^{2}$ \\ ${ }^{1,2}$ Department of Electrical Engineering, Aravali Institute of Technical Studies, Udaipur, India
}

Abstract- Distribution network is one of the main part of power systems as it is connected directly to the load center. The concept of integrating renewable and distributed energy sources in distributed level is a great concern for the power system engineer nowadays. Further research by power companies and engineers is ongoing to apply better techniques to improve power quality and stability of power system in distribution network. This paper presents a review of fundamental distributed network architecture including radial, ring and meshed distributed network looking at the concept of distributed network architecture, types, operation, controlling, management, growth model, advantages and disadvantages of existing distributed networks.

Keywords: Distribution system planning, Load characteristics, Sub transmission Lines, Distribution substations, Design of primary and secondary Systems, Distribution system operation.

\section{INTRODUCTION}

Electric power distribution is the final stage in the delivery of electric power; it carries electricity from the transmission system to individual consumers. Distribution substations connect to the transmission system and lower the transmission voltage to medium voltage ranging between $2 \mathrm{kV}$ and $35 \mathrm{kV}$ with the use of transformers.[1] Primary distribution lines carry this medium voltage power to distribution transformers located near the customer's premises. Distribution transformers again lower the voltage to the utilization voltage used by lighting, industrial equipment and household appliances. Often several customers are supplied from one transformer through secondary distribution lines. Commercial and residential customers are connected to the secondary distribution lines through service drops. Customers demanding a much larger amount of power may be connected directly to the primary distribution level or the subtransmission level.

\section{TYPES OF DISTRIBUTION SYSTEM}

$>$ Radial distribution system.

$>$ Loop distribution system.

$>$ Network distribution system.

\subsection{Radial Distribution System}

A system whereby power is received at the utility supply voltage level by a single, incoming substation. Through a series of step downs and splits, the power is converted for individual end-use equipment.

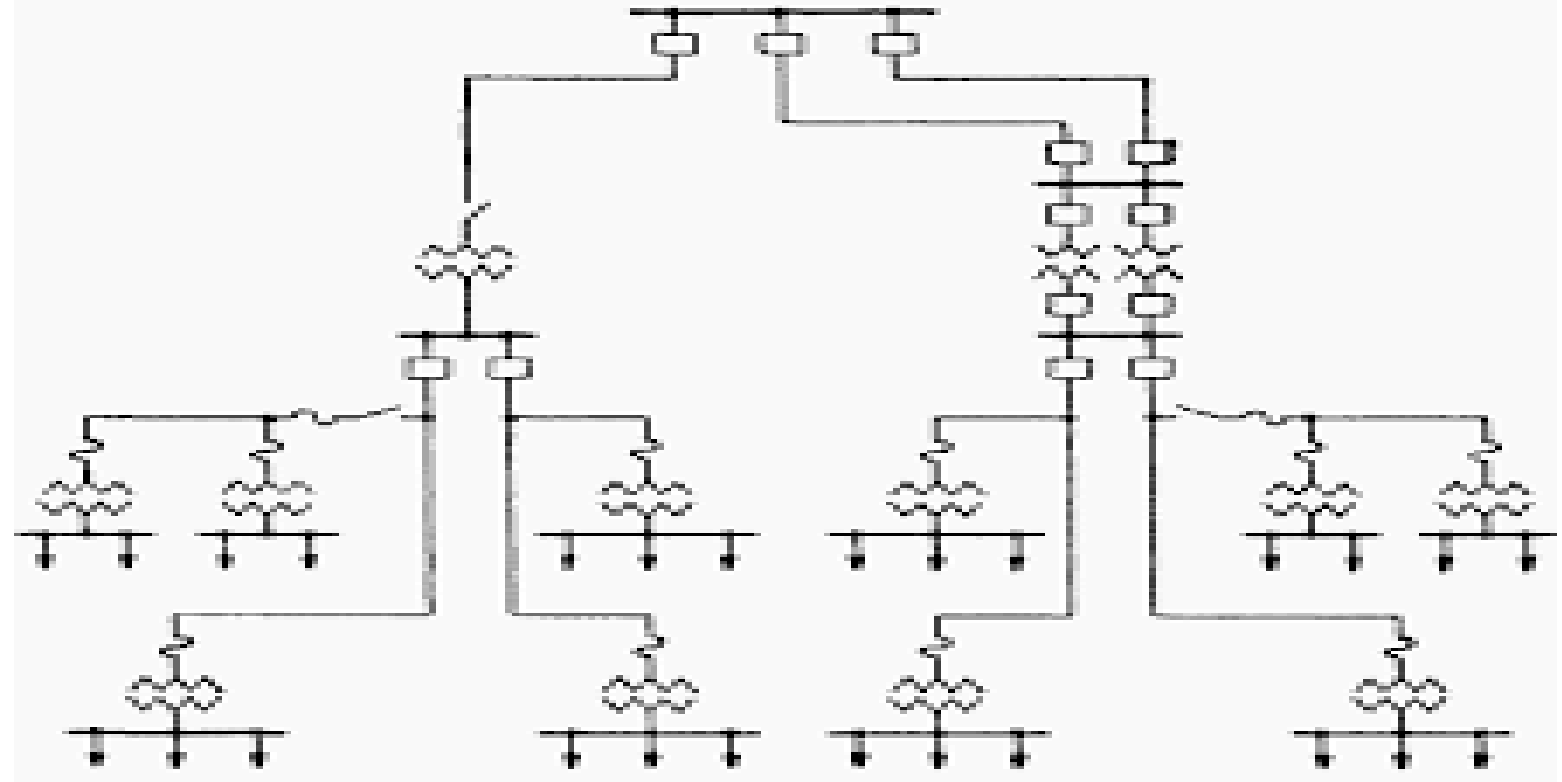

Fig. 2.1 Radial Distribution System 
SCRDSI-2021, Aravali Institute of Technical Studies, Udaipur (Rajasthan), India

International Journal of Technical Research \& Science (Special Issue) ISSN No.:2454-2024 (online)

\subsection{Loop Distribution System}

A loop system, as the name implies, loops through the service area and returns to the original point. The loop is usually tied into an alternate power source. By placing switches in strategic locations, the utility can supply power to the customer from either direction.

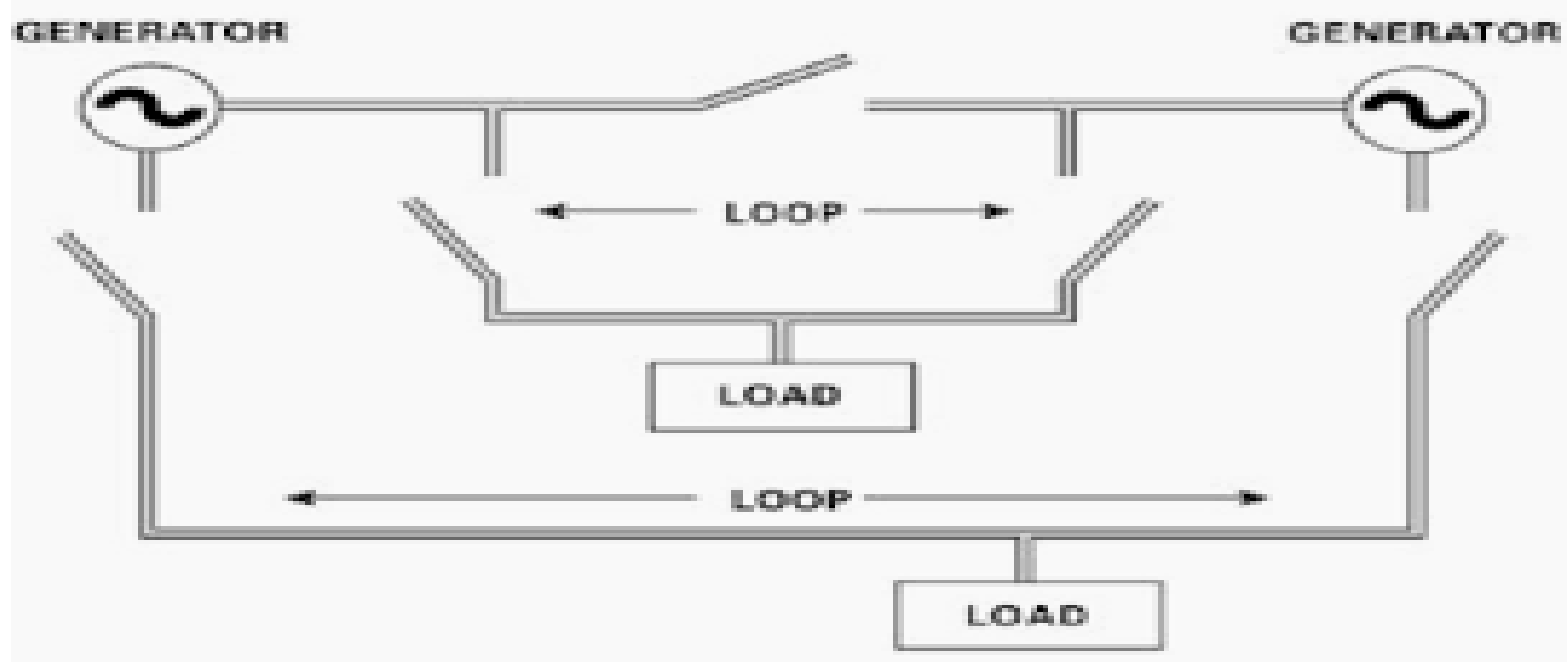

Fig. 2.2 Loop Distribution System

\section{NETWORK DISTRIBUTION SYSTEM}

The network is the most flexible type of primary system; it provides the best service reliability to the distribution transformers or load centre, particularly when the system is supplied from two or more distribution substations.

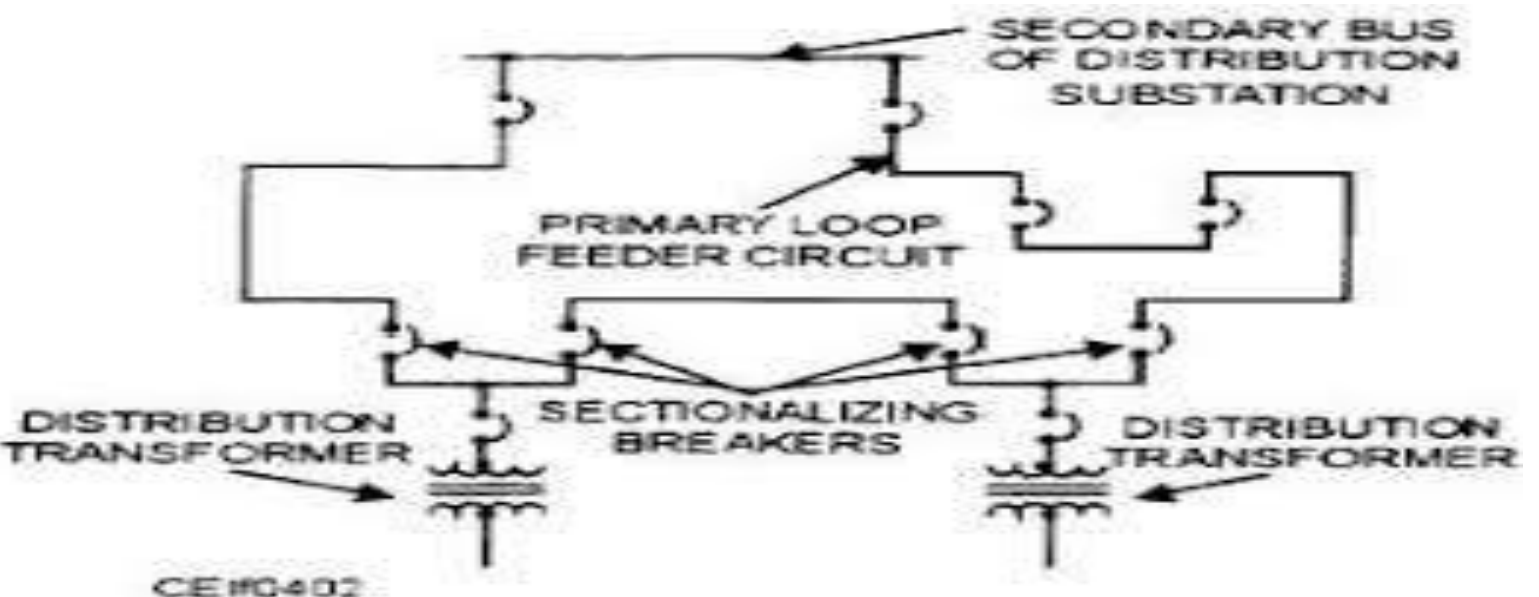

Fig. 3.1 Network distribution system

\subsection{Power Distribution System}

A distribution substation is located near or inside city/town/village/industrial area. It receives power from a transmission network. The high voltage from the transmission line is then stepped down by a stepdown transformer to the primary distribution level voltage. Primary distribution voltage is usually $11 \mathrm{kV}$, but can range between $2.4 \mathrm{kV}$ to $33 \mathrm{kV}$ depending upon region or consumer.

A typical power distribution system consists of -

$>$ Feeders

$>$ Distributor

Service mains

\subsection{Distribution feeders}

The stepped-down voltage from the substation is carried to distribution transformers via feeder conductors. Generally, no tapping's are taken from the feeders so that the current remains same throughout. The main consideration in designing of a feeder conductor is its current carrying capacity.

\subsection{Distributors}

Output from a distribution transformer is carried by distributor conductor. Tapping's are taken from a distributor conductor for power supply to the end consumers. The current through a distributor is not constant as tapping's

DOI Number: https://doi.org/10.30780/specialissue-SCRDSI-2021/002

pg. 5 
are taken at various places throughout its length. So, voltage drop along the length is the main consideration while designing a distributor conductor.

\subsection{Service mains}

It is a small cable which connects the distributor conductor at the nearest pole to the consumer's end.

The above figure shows a simple radial AC power distribution system. The figure does not show other equipment like circuit breakers, measuring instruments etc.

For simplicity purpose.

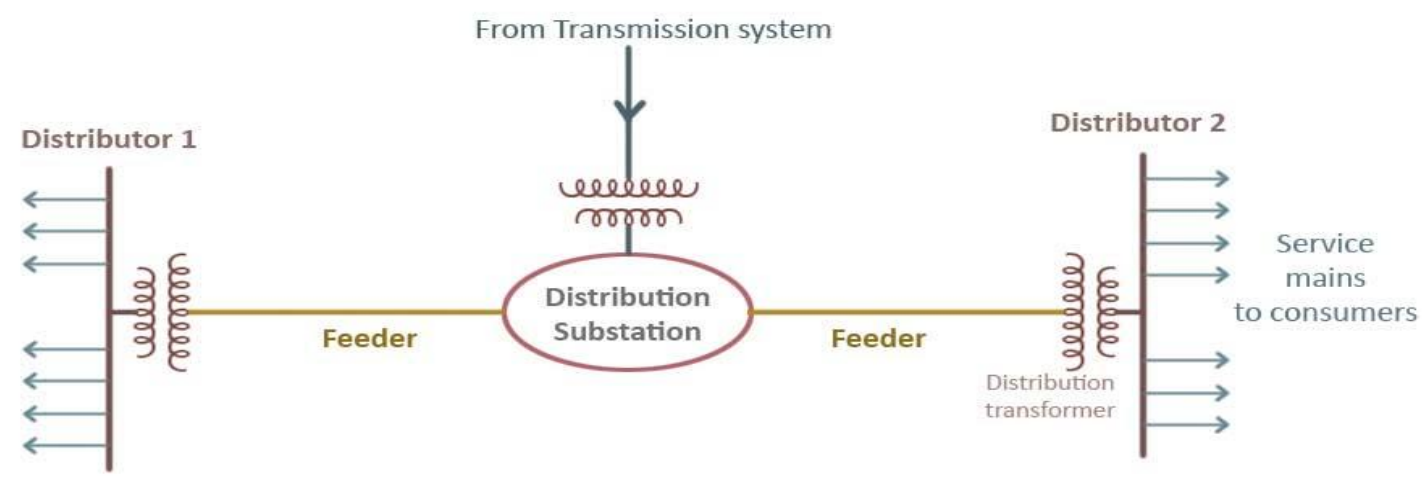

Fig. 3.2 service mains

\section{CLASSIFICATION OF POWER DISTRIBUTION SYSTEMS}

$>$ According to nature of current:

$\circ$ DC distribution system
$\circ$ AC distribution system

$>$ According to type of construction:

- Overhead distribution system

- Underground distribution system

$>$ On the basis of scheme of connection:
- Radial distribution system
○ Ring main distribution system
- Inter-connected distribution system

\subsection{DC distribution system}

The DC distribution system has been proposed, as a replacement for the present AC power distribution system for ships with electric propulsion.

This concept represents a new way of distributing energy for low-voltage installations on ships. It can be used for any electrical ship application up to 20 megawatts and operates at a nominal voltage of $1000 \mathrm{~V}$ DC. The DC distribution system is simply an extension of the multiple DC links that already exist in all propulsion and thruster drives, which usually account for more than 80 percent of the electrical power consumption on electric propulsion vessels.

\subsection{AC distribution system}

Now-a-days electrical energy is generated, transmitted and distributed in the form of alternating current. One important reason for the widespread use of alternating current in preference to direct current is the fact that alternating voltage can be conveniently changed in magnitude by means of a transformer. Transformer has made it possible to transmit a.c. power at high voltage and utilise it at a safe potential. High transmission and AC Distribution System voltages have greatly reduced the current in the conductors and the resulting line losses.

There is no definite line between transmission and distribution according to voltage or bulk capacity. However, in general, the AC Distribution System is the electrical system between the step-down substation fed by the transmission system and' the consumers' meters. The AC Distribution System is classified into:-

1. Primary distribution system

2. Secondary distribution system

\subsubsection{Primary distribution system}

Primary distribution system: It is that part of AC Distribution System which operates at voltages somewhat higher than general utilisation and handles large blocks of electrical energy than the average low-voltage

DOI Number: https://doi.org/10.30780/specialissue-SCRDSI-2021/002

pg. 6 
SCRDSI-2021, Aravali Institute of Technical Studies, Udaipur (Rajasthan), India

International Journal of Technical Research \& Science (Special Issue) ISSN No.:2454-2024 (online) consumer uses. The voltage used for primary distribution depends upon the amount of power to be conveyed and the distance of the substation required to be fed. The most commonly used primary distribution voltages are $11 \mathrm{kV}, 6.6 \mathrm{kV}$ and $3.3 \mathrm{kV}$. Due to economic considerations, primary distribution is carried out by 3-phase, 3wire system.

A typical primary distribution system. Electric power from the generating station is transmitted at high voltage to the substation located in or near the city. At this substation, voltage is stepped down to $11 \mathrm{kV}$ with the help of step-down transformer. Power is supplied to various substations for distribution or to big consumers at this voltage. This forms the high voltage distribu-tion or primary distribution.

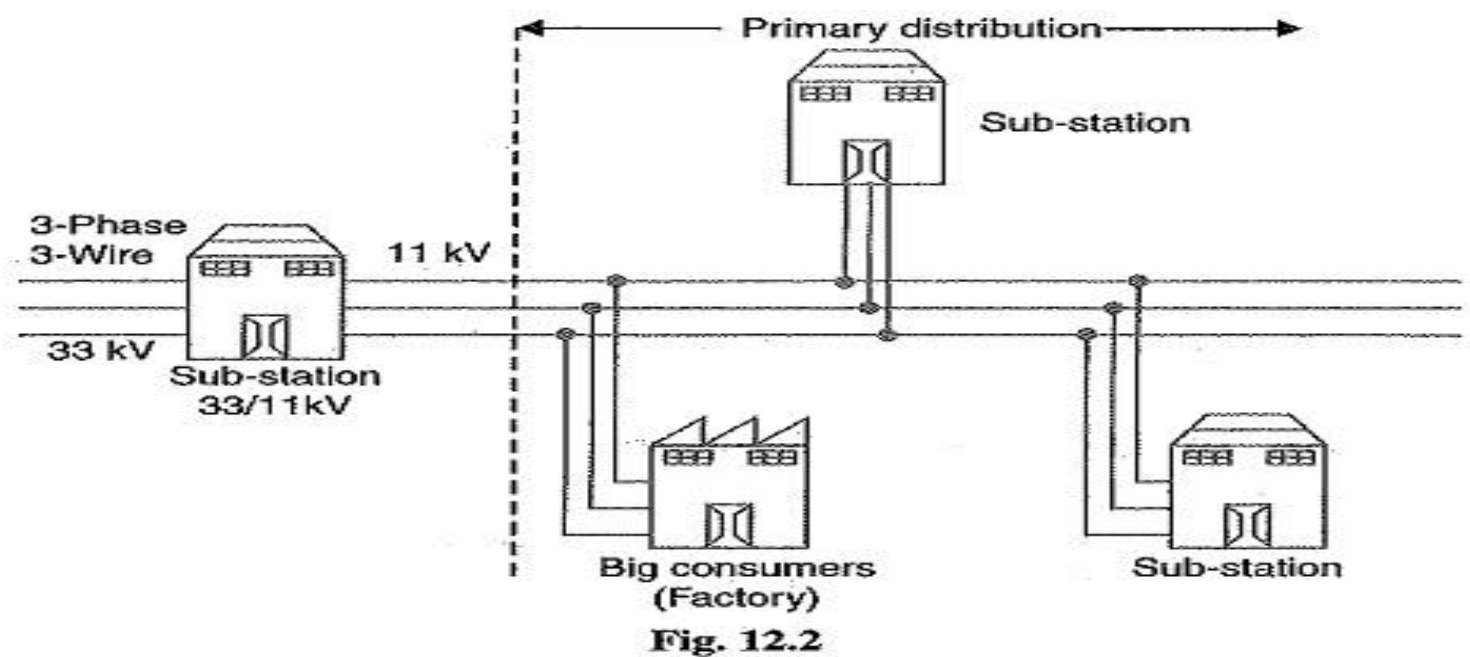

Fig. 4.1 primary distribution system

\subsubsection{Secondary Distribution System}

It is that part of AC Distribution System which includes the range of voltages at which the ultimate consumer utilizes the electrical energy delivered to him. The secondary distribution employs 400/230 V, 3-phase, 4-wire system.

A typical secondary distribution system. The primary distribution circuit delivers power to various substations, called distribution substations. The substations are situated near the consumer's localities and contain step-down transformers. At each distribution substation, the voltage is stepped down to $400 \mathrm{~V}$ and power is delivered by 3phase,4-wire a.c. system. The voltage between any two phases is $400 \mathrm{~V}$ and between any phase and neutral is $230 \mathrm{~V}$. The single phase domestic loads are connected between any one phase and the neutral, whereas 3-phase $400 \mathrm{~V}$ motor loads are connected across 3- phase lines directly.

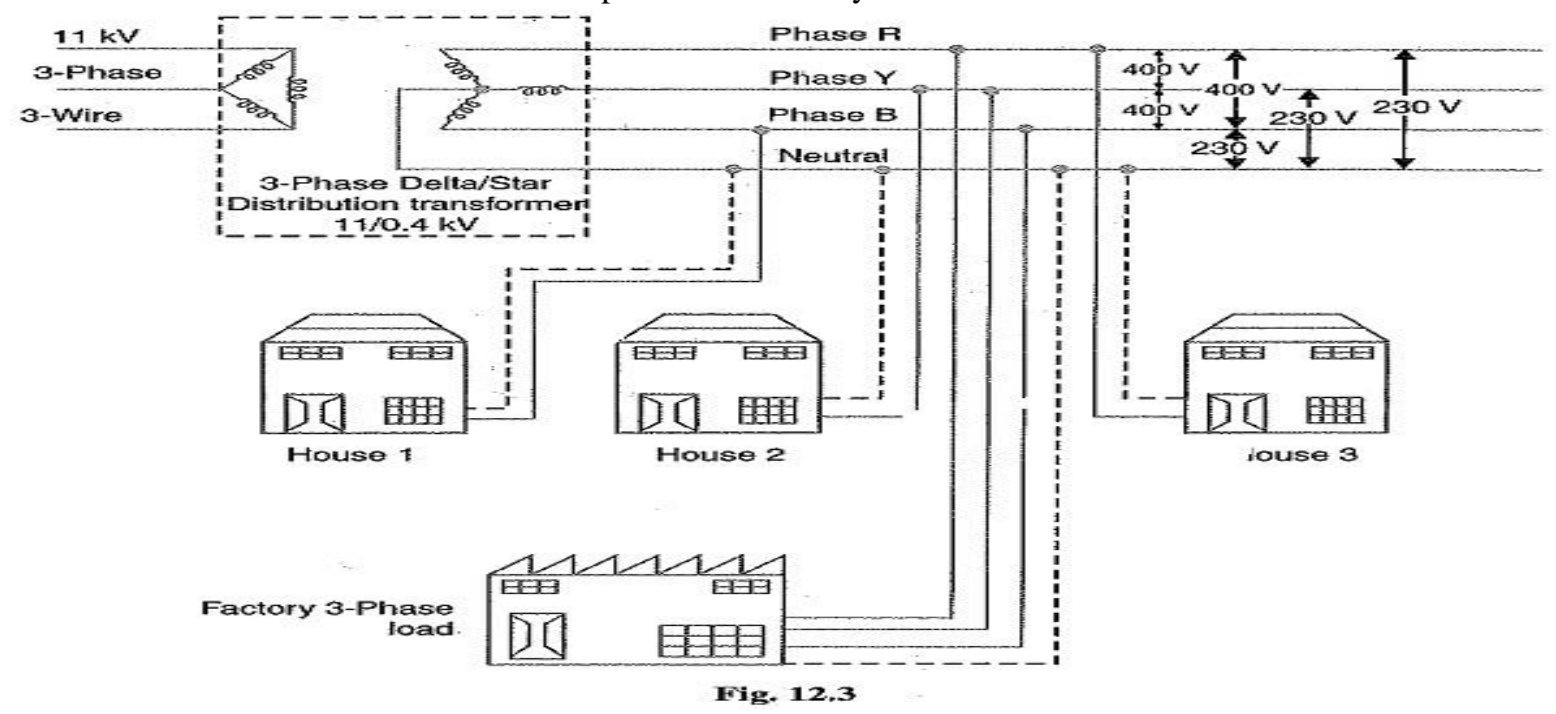

Fig. 4.2 Secondary Distribution System

\subsection{Overhead Distribution System}

An overhead power line is a structure used in electric power transmission and distribution to transmit electrical energy across large distances. It consists of one or more uninsulated electrical cables (commonly multiples of three for three-phase power) suspended by towers or poles.

Since most of the insulation is provided by the surrounding air, overhead power lines are generally the least costly method of power transmission for large quantities of electric energy.

DOI Number: https://doi.org/10.30780/specialissue-SCRDSI-2021/002

pg. 7

Paper Id: IJTRS-SCRDSI-21-002

@ 2017, IJTRS All Right Reserved, www.ijtrs.com 
SCRDSI-2021, Aravali Institute of Technical Studies, Udaipur (Rajasthan), India

International Journal of Technical Research \& Science (Special Issue) ISSN No.:2454-2024 (online)

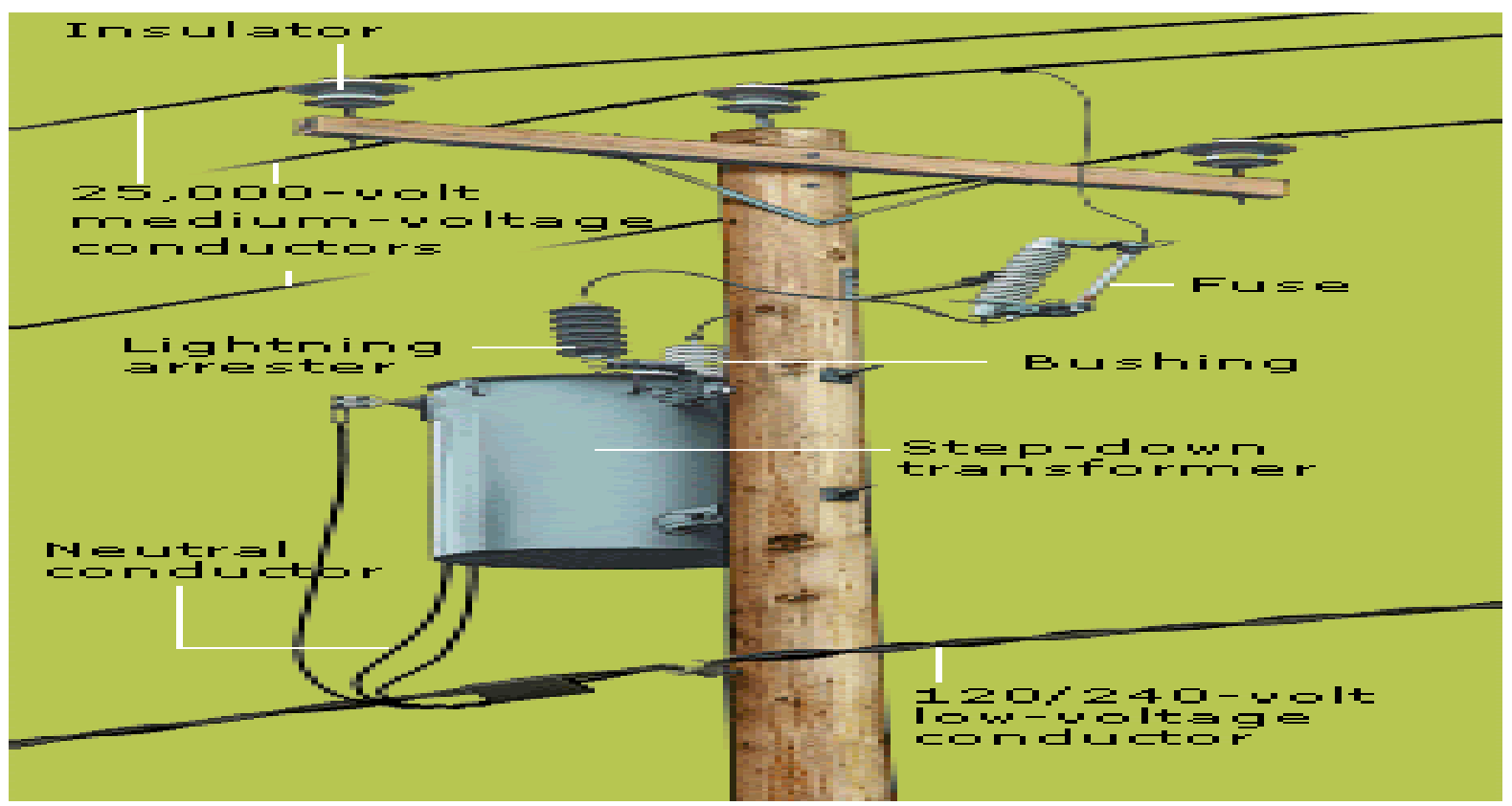

Fig. 4.3 Overhead distribution system

\subsection{Underground Distribution System}

Undergrounding is the replacement of overhead cables providing electrical power or telecommunications, with underground cables. It demonstrates the higher technology in developed countries for fire prevention and to make the power lines less susceptible to outages during high wind thunderstorms or heavy snow or ice storms. An added benefit of undergrounding is the aesthetic quality of the landscape without the powerlines. Undergrounding can increase the initial costs of electric power transmission and distribution but may decrease operational costs over the lifetime of the cables.

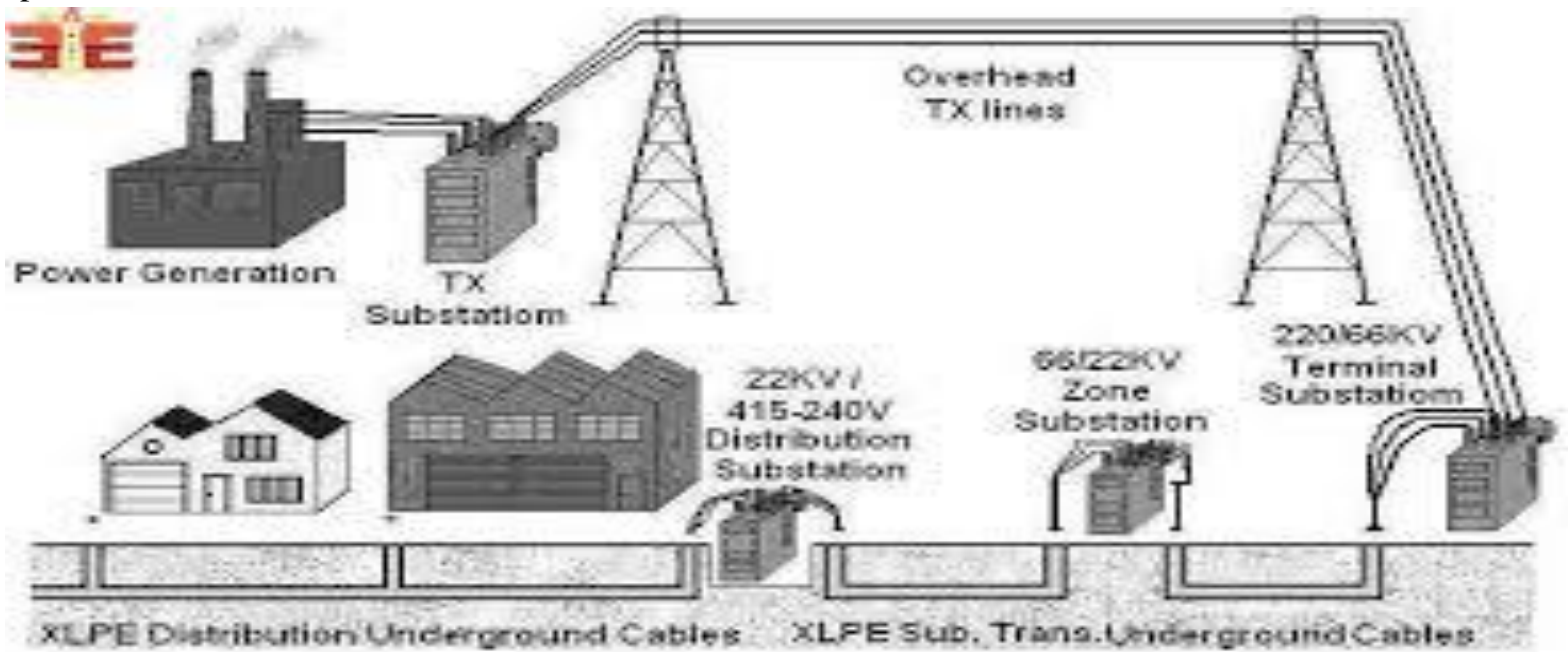

Fig. 4.4 Underground distribution system

\section{APPLICATIONS OF DISTRIBUTED SYSTEMS}

\subsection{Telecommunication networks}

$>$ Telephone networks and cellular networks.

$>$ Computer networks such as the Internet.

$>$ Wireless sensor networks.

$>$ Routing algorithms.

5.2 Network applications

$>$ World Wide Web and peer-to-peer networks.

$>$ Massively multiplayer online games and virtual reality communities.

$>$ Distributed databases and distributed database management systems.

$>$ Networks file systems.

5.3 Real-time process control

$>$ Aircraft control systems.

$>$ Industrial control systems

DOI Number: https://doi.org/10.30780/specialissue-SCRDSI-2021/002

Paper Id: IJTRS-SCRDSI-21-002

pg. 8

@2017, IJTRS All Right Reserved, www.ijtrs.com 


\subsection{Parallel computation}

$>$ Scientific computing including cluster computing and grid computing.

\section{CONCLUSION}

The concept of distributed computing is the most efficient way to achieve the optimization. Distributed computing is anywhere: intranet, Internet or mobile ubiquitous computing (laptop, PDAS, pagers, smart watches, hi-fi systems). It deals with hardware and software systems that contain more than one processing / storage and run in concurrently. Main motivation factor is resource sharing; such as files, printers, web pages or database records. Grid computing and cloud computing are form of distributed computing.

\section{REFERENCES}

[1] Hassaine, L.,Olias, E., Quintero, J.,Salas, V. Overview of power inverter topologies and control structures for grid connected photovoltaic systems. Renew. Sustain. Energy Rev. 2014, 30, 796-807. [CrossRef]

[2] Ellabban, O.; Abu-Rub, H.,Blaabjerg, F. Renewable energy resources: Current status, future prospects and their enabling technology. Renew. Sustain. Energy Rev. 2014, 39, 7488.

[3] Zeb, K.; Uddin, W.; Khan, M.A.; Ali, Z.; Ali, M.U.; Christofides, N.; Kim, H.J. A comprehensive review on inverter topologies and control strategies for grid connected photovoltaic system. Renew. Sustain. EnergyRev. 2018, 94, 1120-1141. [CrossRef]Energies 2018, 11, 196830.

[4] Kumar, P., Mathew, L., Shimi, S. L., \& Singh, P. (2016). Need of ICT for Sustainable Development of Power Sector. Proceedings of International Conference on ICT for Sustainable Development, 607614. doi:10.1007/978-981-10-0129-1_63.

[5] P. Kumar and V. Kumar, "Energy storage options for enhancing the reliability of Power system in the presence of Renewable Energy Sources," 2020 Second International Conference on Inventive Research in Computing Applications (ICIRCA), Coimbatore, India, 2020, pp. 1071-1076, doi: 10.1109/ICIRCA48905.2020.9183349. 